\title{
A Kinetic Study of Oxalic Acid Electrochemical Oxidation on a Manganese Dioxide Rotating Cylinder Anode
}

\author{
Ali H. Abbar ${ }^{a}$ and Ammar S. Abbas ${ }^{b, *}$ \\ ${ }^{a}$ Chemical Engineering Department, University of Al-Qadisiyah, Iraq \\ ${ }^{b}$ Chemical Engineering Department, University of Baghdad, Iraq
}

Received February 17, 2017; accepted November 10, 2017

\begin{abstract}
This paper deals with the theory and kinetics of oxalic acid electrochemical oxidation, in an acidic solution containing sodium chloride, using a manganese dioxide rotating cylinder anode. Voltammetric and galvanostatic electrolysis techniques were used. The voltametric study shows a higher anodic wave corresponding to chlorine oxidation on the $\mathrm{MnO}_{2}$ electrode, prevailing oxalic acid indirect oxidation. Galvanostatic electrolysis studies confirmed that the rate constant is affected by chloride concentration, current density, agitation and temperature. Electrochemical oxidation rate was found to be a pseudo-first order kinetic process. A strongly linear relationship between the rate constant and chloride concentration was observed, while polynomial relations, with respect to current density and temperature, were found. The activation energy was found to be $14.541 \mathrm{~kJ} / \mathrm{mol}$, which suggests a diffusion control kinetic step in oxalic acid degradation. The findings of the present research validate that oxalic acid incineration can be successfully carried out on a $\mathrm{MnO}_{2}$ anode, in $\mathrm{NaCl}$ presence.
\end{abstract}

Keywords: electrochemical incineration; oxalic acid; manganese dioxide; sodium chloride; pseudo-kinetics and activation energy.

\section{Introduction}

Oxalic acid (OA) is one of the most toxic organic compounds. OA has several manufacturing and industrial uses, including: printing and dyeing fabrics; straw hats bleaching; paint removing; varnish; rust or ink stains; and wood cleaning. After these industrial processes, this compound is discharged in the water effluents. OA also is the main and final intermediate for the catalytic and electrochemical oxidation of several other organic compounds [1]. Therefore,

\footnotetext{
*Corresponding author. E-mail address: ali.abbar@qu.edu.iq, aammarabbas@coeng.uobaghdad.edu.iq
} 
OA incineration should be done before effluents are discharged into the environment.

Electrochemical technology has shown to be a promising method for the incineration of organic pollutants, such as OA, existing in wastewater [2]. The main reagent here are electrons, which are a clean reagent; consequently, there is no need for adding an extra reagent. Also, the electrochemical process high selectivity prevents the production of unwanted by-products. The reaction is usually carried out at room temperature and at a normal pressure [3].

Several anodic materials have been tested, but most of them presented substantial disadvantages, such as rapid loss of activity (graphite), high cost (Si-borondoped diamond (BDD)), release of toxic ions $\left(\mathrm{PbO}_{2}\right)$, limited service life $\left(\mathrm{SnO}_{2}\right)$ and an incomplete oxidation $\left(\mathrm{IrO}_{2}\right)$ [4, 5]. Therefore, a considerable effort is devoted to investigate cheaper anode materials with comparable performances, to be used in the treatment of wastewater containing organic compounds. Among these, manganese oxides $\left(\mathrm{MnO}_{\mathrm{x}}\right)$ materials represent an attractive family for electrodes manufacture, and they have been successfully used in wastewater treatments and other applications [6-9]. These oxides display excellent electrocatalytic properties, low cost, availability, environmental compatibility and chemical stability [6,7]. Electrodes based on manganese oxide thin films may be obtained by different methods, such as sol-gel [10], physical vapor deposition [11], electrostatic spray deposition [12], electrochemical deposition [13], and chemical bath deposition [14, 15]. The low costs of equipment and the accurate control of the deposited thickness make the electrodeposition method very widely used in manganese dioxide synthesis [13].

In the electrochemical process, pollutants are destroyed by either a direct or indirect oxidation process. It has been generally observed that the direct oxidation of organic compounds at the electrode surface is very difficult, and that the rate of reaction is too slow [4, 16]. Bonfatti et al. [16] showed that OA electrochemical oxidation could be carried out with higher current efficiency at $\mathrm{Pt}$, in the presence of suitable amounts of $\mathrm{NaCl}$. A higher chemical oxygen demand (COD) removal rate was observed when $\mathrm{NaCl}$ was added at a concentration of $1 \mathrm{~g} / \mathrm{L}$ in $\mathrm{OA}$ electrochemical incineration, using a rotating $\mathrm{MnO}_{2}$ anode [7]. Furthermore, pseudo-first-order reaction kinetics was reported for the degradation of various organic compounds, with chloride as a supporting electrolyte $[17,18]$.

\section{Electrochemical oxidation mechanism}

For both direct and indirect carboxylic acids electrochemical oxidation on metal oxide anodes, a generalized degradation mechanism has been proposed by Comminilles [19]. During electrolysis, water molecules dissociate to form an $\mathrm{OH}$ radical with the loss of an electron, and the radical is simultaneously adsorbed onto the metal oxide.

$$
\mathrm{MO}_{x}+\mathrm{H}_{2} \mathrm{O} \rightarrow \mathrm{MO}_{x}(\mathrm{OH})+\mathrm{H}^{+}+e^{-}
$$


This is termed as physisorbed active oxygen. In the second step, the adsorbed hydroxide radicals react with the oxygen already present in the metal oxide anode, causing the transition of oxygen from the adsorbed hydroxyl radical to the lattice of the oxide anode, to form a higher oxide.

$$
M O_{x}(\cdot O H) \rightarrow M O_{x+1}+H^{+}+e^{-}
$$

This is called as chemisorbed active oxygen, which reacts with carboxylic acids and converts them into $\mathrm{CO}_{2}$ and other intermediate products. The formed products undergo further oxidation in a similar way; thereby, complete oxidation takes place. Comminilles [19] also reported that chemisorbed active oxygen $\left(\mathrm{MO}_{\mathrm{x}+1}\right)$ is involved in the formation of particular oxidation products. If there is no oxidizable organic compound present in the medium, active oxygen on the oxide anode of both physisorbed and chemisorbed will liberate dioxygen, according to equations (3) and (4).

$$
\begin{gathered}
M O_{x}(. O H) \rightarrow 1 / 2 O_{2}+H^{+}+e^{-}+M O_{x} \\
M O_{x+1} \rightarrow M O_{x}+1 / 2 O_{2}
\end{gathered}
$$

In the same way, an indirect oxidation mechanism has been proposed for the oxide anode, with chloride as a supporting electrolyte for the removal of organic pollutants from waste water [20]:

$$
\begin{gathered}
2 \mathrm{Cl}^{-} \rightarrow \mathrm{Cl}_{2}+2 \mathrm{e}^{-} \text {(anode) } \\
\mathrm{Cl}_{2}+\mathrm{H}_{2} \mathrm{O} \rightarrow \mathrm{HOCl}+\mathrm{Cl}^{-}+\mathrm{H}^{+}(\text {solution }) \\
\mathrm{MO}+\mathrm{HOCl} \rightarrow \mathrm{MO}(\cdot \mathrm{OCl})+\mathrm{H}^{+}+e^{-}(\text {physisorbed }) \\
\mathrm{MO}_{x}(\cdot \mathrm{OCl}) \rightarrow \mathrm{MO}_{x+1}+\mathrm{Cl}^{-}+e^{-}(\text {chemisorbed }) \\
\mathrm{MO}_{x}(\cdot \mathrm{OCl}) \rightarrow 1 / 2 \mathrm{O}_{2}+\mathrm{MO}_{x}+\mathrm{Cl}^{-}+e^{-} \\
\mathrm{MO} \mathrm{O}_{x+1} \rightarrow \mathrm{MO}_{x}+1 / 2 \mathrm{O}_{2}
\end{gathered}
$$

Physisorbed ${ }^{\circ} \mathrm{OCl}$ radicals and chemisorbed active oxygen participate in the organic compound degradation.

According to equations (9) and (10), in the absence of any oxidizable organics, the active oxidative species produce dioxygen and chloride ions. In acidic conditions, chlorine is the main oxidative agent for organic matter oxidation. In alkaline solutions, $\mathrm{OCl}^{-}, \mathrm{ClO}_{3}{ }^{-}$and free hydroxyl radicals are efficient oxidative agents [21]. The direct oxidation of organic compounds and its attack by the hydroxyl radical are negligible, in comparison with the attack by chlorine radicals.

Although some works are available for OA electrochemical oxidation using different anodic materials [7, 22], research on OA kinetic incineration using a 
$\mathrm{MnO}_{2}$ anode is not available. In the present work, a study of OA incineration kinetics by indirect electrochemical oxidation with a $\mathrm{MnO}_{2}$ electrode is reported.

\section{Material and methods}

All chemicals used in the experiments were of reagent grade, and there was no need for further purification. $\mathrm{MnSO}_{4} \cdot \mathrm{H}_{2} \mathrm{O}$ (Thomas Baker), $\mathrm{H}_{2} \mathrm{SO}_{4}$ (RiedeldeHaën), OA (LOBA Chemie), $\mathrm{NaCl}$ (Thomas Baker) and distilled water were used in the preparation of all aqueous solutions.

Manganese dioxide was electroplated on a graphite rod of $1.98 \mathrm{~cm}$ diameter and a $32.3 \mathrm{~cm}^{2}$ active surface area, by anodic deposition on an acidified sulfate bath $\left(100 \mathrm{~g} / \mathrm{L} \mathrm{MnSO}_{4-} 90 \mathrm{~g} / \mathrm{L} \mathrm{H}_{2} \mathrm{SO}_{4}\right.$ ). Details of experimental and used apparatus were described in a previous work [7].

Cyclic voltammetries were performed in a conventional three-electrode cell (Pyrex ${ }^{\circledR}$ glass) at room temperature. A manganese dioxide rotating cylinder electrode, with a submerged area of $12.3 \mathrm{~cm}^{2}$ rotated at $200 \mathrm{rpm}$, was used as working electrode. A platinum plate $\left(0.35 \mathrm{~cm}^{2}\right)$ and a saturated calomel electrode were used as counter and reference electrode, respectively. Electrochemical experiments were controlled with a potentiostat PGSTAT30 (Autolab) at a scan rate of $100 \mathrm{mV} / \mathrm{s}$. Potential values referred to a saturated calomel electrode (SCE).

OA bulk oxidation was performed in a single-body, thermostated Pyrex glass cell of 0.75 liter; the anode was a $\mathrm{MnO}_{2}$ rotating cylinder electrode, with a submerged area of $32.3 \mathrm{~cm}^{2}$, and the supporting electrolyte was $0.5 \mathrm{M} \mathrm{Na}_{2} \mathrm{SO}_{4}$ containing 0.1 M OA. The final $\mathrm{pH}$ value was 2 , adjusted by adding a $1 \mathrm{M} \mathrm{NaOH}$ or $\mathrm{H}_{2} \mathrm{SO}_{4}$ solution. The $\mathrm{pH}$ was kept constant at this value during electrolysis. The total volume of the electrolyte was 0.6 liter at each run. A hollow nickel cylinder with an inside diameter of $8 \mathrm{~cm}$ and length of $12 \mathrm{~cm}$ was used as counter electrode. The galvanostatic experiments of OA electro-oxidation were performed using a DC power supply (UNI-T: UTP3315TF-L). The effect of $\mathrm{NaCl}$ concentration in the range of 1 to $5 \mathrm{~g} / \mathrm{L}$ was investigated at a constant current density of 30 $\mathrm{mA} / \mathrm{cm}^{2}$, while current densities in the range of 10 to $60 \mathrm{~mA} / \mathrm{cm}^{2}$ were applied for studying the effect of current density (I) on the reaction rate constant. The effect of electrode rotation speed $(\omega)$ was investigated in the range of 0 to 400 rpm using an electrical gearbox stirrer (Heidolph) with an electronic tachometer. Furthermore, temperature effect (T) was investigated in the range from 25 to 60 ${ }^{\circ} \mathrm{C}$. During the electrolysis, OA residual content was determined using a conventional titration method with $\mathrm{KMnO}_{4}$ [22].

\section{Results and discussion}

\section{Anode cyclic voltammograms performance}

In order to have some preliminary information on the reactivity of active chlorine with oxalic acid, some cyclic voltammograms were recorded with and without $\mathrm{NaCl}$ and $\mathrm{OA}$ addition at the $\mathrm{MnO}_{2}$ anode in acidic conditions. As shown in Fig. 1, the addition of $\mathrm{NaCl}$ to a water solution produces a higher anodic wave. According to literature, such behavior can be attributed to the oxidation of $\mathrm{Cl}$ 
ions to $\mathrm{Cl}_{2}$ [23]. The same cyclic voltammetry behavior was obtained by Scialdone et al. [24], when OA, at a concentration of $5 \mathrm{mM}$, was incinerated on an $\mathrm{IrO}_{2}-\mathrm{Ta}_{2} \mathrm{O}_{5}$ anode; however, the anodic wave in the present work was higher, due to the used OA higher concentration.

Results of the previous work [7] showed that $\mathrm{NaCl}$ addition led to an increase in COD removal percentage from $26.40 \%$, in the case of free $\mathrm{NaCl}$, to $79.50 \%$, with the addition of $1 \mathrm{~g} / \mathrm{L}$ of $\mathrm{NaCl}$. This increase in COD removal is an indication of the effective role of $\mathrm{NaCl}$ during $\mathrm{OA}$ indirect oxidation, when the $\mathrm{MnO}_{2}$ anode was used, as a result of chlorine overpotential on this electrode, which enables more chlorine molecules to attack OA.

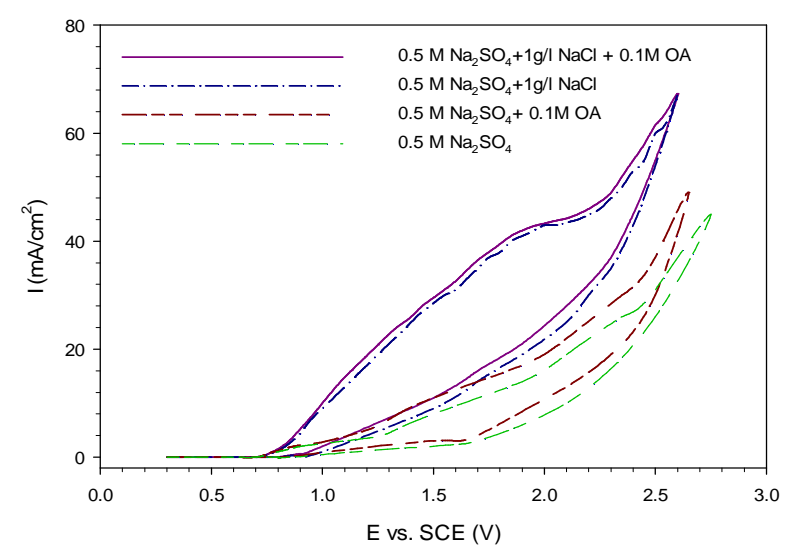

Figure 1. Cyclic voltammograms performed at $\mathrm{MnO}_{2}$ anode. Scan rate $=100 \mathrm{mV} / \mathrm{s}, \mathrm{T}=$ $25^{\circ} \mathrm{C}$ and $\omega=200 \mathrm{rpm}$.

\section{Indirect electrochemical oxidation kinetics}

In indirect electrochemical oxidation, OA removal rate is proportional to OA concentration, and also to chlorine/hypochlorite concentration, since the latter mediated indirect oxidation. OA removal rate can be written as:

$$
\frac{-d[O A]}{d t}=k[O A]\left[\mathrm{Cl}_{2}\right]
$$

Electrochemical treatment involves the application of an electric current to the effluent, to convert chloride to chlorine and hypochlorite. Chlorine and hypochlorite will oxidize OA, and be reduced to a chloride ion. The process is then repeated in a cyclic way. Chlorine/hypochlorite concentration during electrolysis is assumed to be constant, and so, equation (11) can be written as a pseudo-first order kinetics equation.

$$
\frac{-d[O A]}{d t}=k_{o b s}[\mathrm{OA}]
$$

The integration of equation (12) leads to a natural logarithmic relation between OA concentration and time, as follows,

$$
\ln \frac{[O A]_{t}}{[O A]_{0}}=-k_{o b s} t
$$

which could be written as an exponential decay function: 


$$
\frac{[O A]_{t}}{[O A]_{0}}=e^{-k_{0 b s} t}
$$

By using non-linear least squared fittings (exponential decay) of the untransformed original equation (Eq.14), the observed rate constant $\mathrm{k}_{\mathrm{obs}}\left(\mathrm{min}^{-1}\right)$ value can be estimated [25].

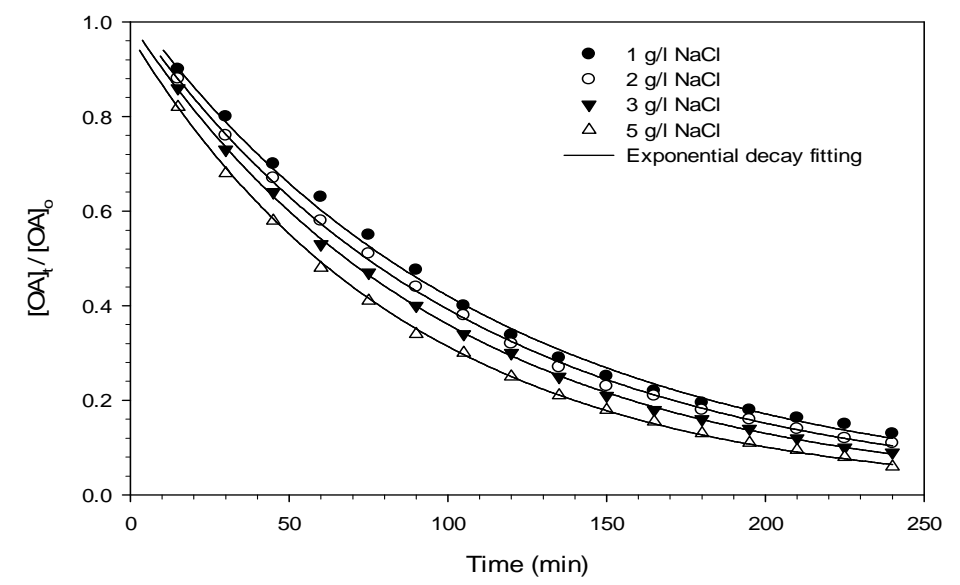

Figure 2. Normalized concentration $[\mathrm{OA}]_{\mathrm{t}} /[\mathrm{OA}]_{\mathrm{o}}$ against time curves, obtained at $\mathrm{I}=30$ $\mathrm{mA} / \mathrm{cm}^{2}, \omega=200 \mathrm{rpm}, \mathrm{T}=25^{\circ} \mathrm{C}$ and $[\mathrm{OA}]=0.1 \mathrm{M}$, for different sodium chloride concentrations.

\section{Effect of $\mathrm{NaCl}$ concentration on $\mathrm{OA}$ removal}

Fig. 2 illustrates the decrease in normalized OA concentration, $[\mathrm{OA}]_{\mathrm{t}} /[\mathrm{OA}]_{\mathrm{o}}$, plotted against electrolysis time, with their exponential decay fitting, using different $\mathrm{NaCl}$ concentrations. Table 1 and Fig. 3 show the rate constant against chloride concentration. The increase in chloride concentration in the electrolytic solution leads to a higher reaction rate. A previous study [26] showed that an increase in chloride concentration reduced the overpotential required for chloride anodic oxidation, resulting in a higher production of hypochlorite. It is clear that there is a strong linearity between the rate constant and chloride concentration. The rate constant reported in Table 1 increased from 0.0091 to $0.011 \mathrm{~min}^{-1}$; when $\mathrm{NaCl}$ concentration rose from 1 to $5 \mathrm{~g} / \mathrm{L}$, the values of $\mathrm{R}^{2}$ varied between 0.9953 and 0.9994 for different chloride concentrations. Huang et al. [27] found the same linear relationship between the rate constant and chloride concentration when OA degraded, using a Ti-DAS net anode. OA removal efficiency increased from 88 to $94 \%$, as $\mathrm{NaCl}$ concentration increased from 1 to $5 \mathrm{~g} / \mathrm{L}$ (Table 1 ). However, using a $\mathrm{NaCl}$ concentration higher than $3 \mathrm{~g} / \mathrm{L}$ is not recommended, because the halogenated organic compound can generate more toxic materials than those of OA [24].

Table 1. Effect of sodium chloride concentrations on the observed rate constant $\left(\mathrm{k}_{\mathrm{obs}}\right)$.

\begin{tabular}{|c|c|c|c|c|c|c|c|}
\hline Parameter & Value & $\begin{array}{c}\text { OA } \\
\text { removal } \\
(\%) \\
\end{array}$ & $\begin{array}{c}\text { Rate constant } \\
\mathbf{k}_{\mathrm{obs}} \\
\left(\mathrm{min}^{-1}\right) \times 10^{3} \\
\end{array}$ & $\begin{array}{c}\text { Standard } \\
\text { error of } \\
k_{\text {obs }} \\
\end{array}$ & $\mathbf{R}^{2}$ & $\begin{array}{c}\text { Sum of } \\
\text { square } \\
\times 10^{3}\end{array}$ & Conditions \\
\hline \multirow{4}{*}{$\begin{array}{c}\text { Sodium } \\
\text { chloride } \\
\text { concentration } \\
(\mathrm{g} / \mathrm{L})\end{array}$} & 1 & 88 & 9.09 & $1.8 * 10^{-2}$ & 0.9953 & 0.0099 & \multirow{4}{*}{$\begin{array}{c}\mathrm{I}=30 \mathrm{~mA} / \mathrm{cm}^{2}, \\
\omega=200 \mathrm{rpm}, \\
\mathrm{T}=25^{\circ} \mathrm{C}, \\
{[\mathrm{OA}]=0.1 \mathrm{M}}\end{array}$} \\
\hline & 2 & 89 & 9.55 & $9.65 * 10^{-3}$ & 0.9988 & 0.0025 & \\
\hline & 3 & 91 & 10.18 & $6.83 * 10^{-3}$ & 0.9994 & 0.0013 & \\
\hline & 5 & 94 & 11.12 & $8.26^{*} 10^{-3}$ & 0.9992 & 0.0016 & \\
\hline
\end{tabular}




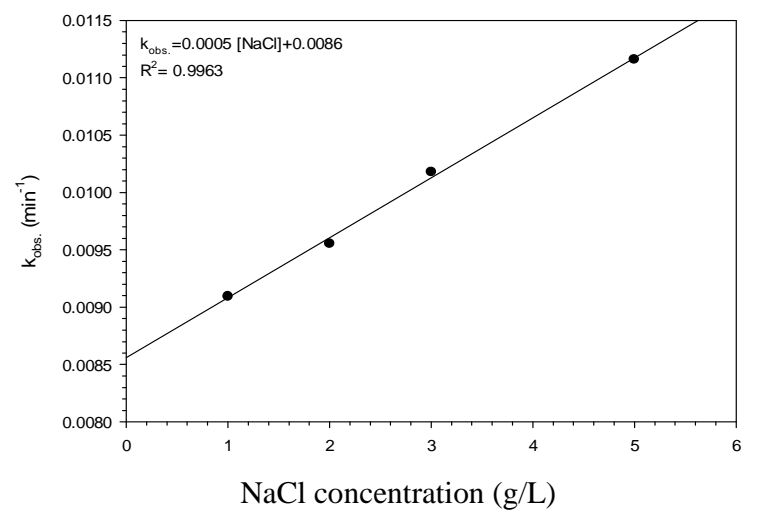

Figure 3. Effect of sodium chloride concentration on the reaction rate of $\mathrm{OA}$ electrochemical incineration; $\mathrm{I}=30 \mathrm{~mA} / \mathrm{cm}^{2}, \omega=200 \mathrm{rpm}, \mathrm{T}=25^{\circ} \mathrm{C}$ and $[\mathrm{OA}]=0.1$ M.

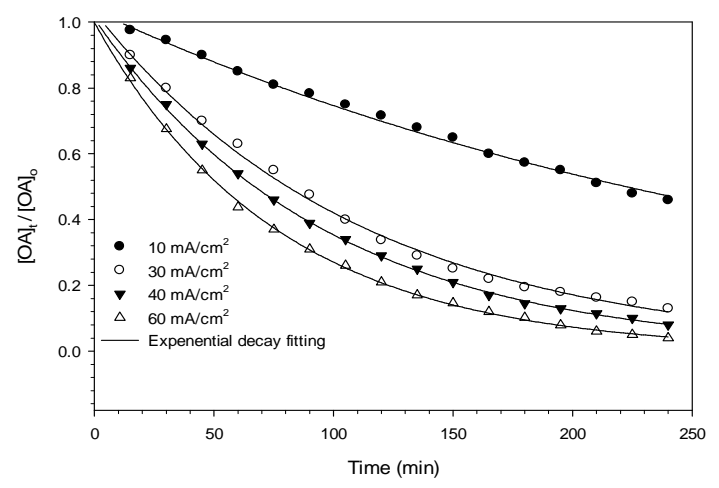

Figure 4. Normalized concentration $[\mathrm{OA}]_{\mathrm{t}} /[\mathrm{OA}]_{\mathrm{o}}$ against time curves, obtained at $[\mathrm{NaCl}]=1 \mathrm{~g} / \mathrm{L}, \omega=200 \mathrm{rpm}, \mathrm{T}=25{ }^{\circ} \mathrm{C}$ and $[\mathrm{OA}]=0.1 \mathrm{M}$, for different current densities.

\section{Effect of current density on $O A$ removal}

Fig. 4 shows the decrease in normalized OA concentration, $[\mathrm{OA}]_{\mathrm{t}} /[\mathrm{OA}]_{\mathrm{o}}$, plotted against electrolysis time, with their exponential decay fitting at different current densities.

The rate constant against the current density is shown in Fig. 5 and Table 2.

In this study, when the current density increases from 10 to $60 \mathrm{~mA} / \mathrm{cm}^{2}$, the rate constant increases from 0.0033 to $0.0131 \mathrm{~min}^{-1}$. The relation between current density and the rate constant was fitted to be a polynomial. The enhancing effect of current density is attributed to the improvement of chlorine/hypochlorite production rate that enhances the indirect oxidation effect during electrolysis. 


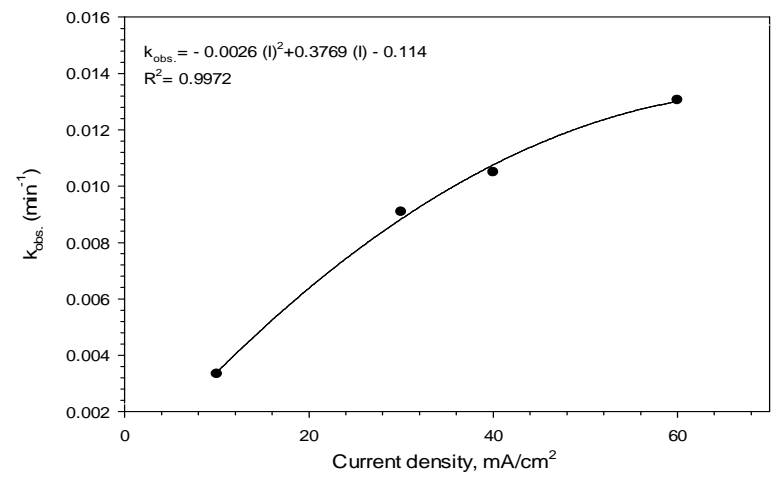

Figure 5. Effect of current density on the rate constant of OA electrochemical incineration; $[\mathrm{NaCl}]=1 \mathrm{~g} / \mathrm{L}, \omega=200 \mathrm{rpm}, \mathrm{T}=25^{\circ} \mathrm{C}$ and $[\mathrm{OA}]=0.1 \mathrm{M}$.

Table 2. Effect of current density on the observed rate constant ( $\left.\mathrm{k}_{\mathrm{obs}}\right)$.

\begin{tabular}{|c|c|c|c|c|c|c|c|}
\hline Parameter & Value & $\begin{array}{c}\text { OA } \\
\text { removal } \\
(\%)\end{array}$ & $\begin{array}{c}\text { Rate constant } \\
\mathbf{k}_{\text {obs }} \\
\left(\mathbf{m i n}^{-1}\right) \mathbf{x} 10^{3} \\
\end{array}$ & $\begin{array}{c}\text { Standard } \\
\text { error of } \\
\mathbf{k}_{\text {obs }} \\
\end{array}$ & $\mathbf{R}^{2}$ & $\begin{array}{c}\text { Sum of } \\
\text { square } \\
\mathbf{x 1 0}^{3}\end{array}$ & Conditions \\
\hline \multirow{4}{*}{$\begin{array}{c}\text { Current } \\
\text { density } \\
\left(\mathrm{mA} / \mathrm{cm}^{2}\right)\end{array}$} & 10 & 54 & 3.34 & $5.82 * 10^{-5}$ & 0.9958 & 2.50 & \multirow{4}{*}{$\begin{array}{c}{[\mathrm{NaCl}]=1 \mathrm{~g} / \mathrm{L}} \\
\omega=200 \mathrm{rpm}, \\
\mathrm{T}=25^{\circ} \mathrm{C}, \\
{[\mathrm{OA}]=0.1 \mathrm{M}}\end{array}$} \\
\hline & 30 & 88 & 9.09 & $1.64 * 10^{-4}$ & 0.9953 & 9.09 & \\
\hline & 40 & 92 & 10.50 & 0.000 & 1.0000 & 0.00 & \\
\hline & 60 & 96 & 13.10 & $1.22 * 10^{-4}$ & 0.9988 & 2.87 & \\
\hline
\end{tabular}

Huang et al. [26] found a linear relationship between the rate constant and the current density when OA degraded, using a Ti-DAS net anode in $\mathrm{NaCl}$ presence. According to data in Table 2, OA removal percentage increased from 54 to $96 \%$, as the current density increased from 10 to $60 \mathrm{~mA} / \mathrm{cm}^{2}$. This result is an indication that the current density is the most important factor in OA incineration in the presence of chloride ions.

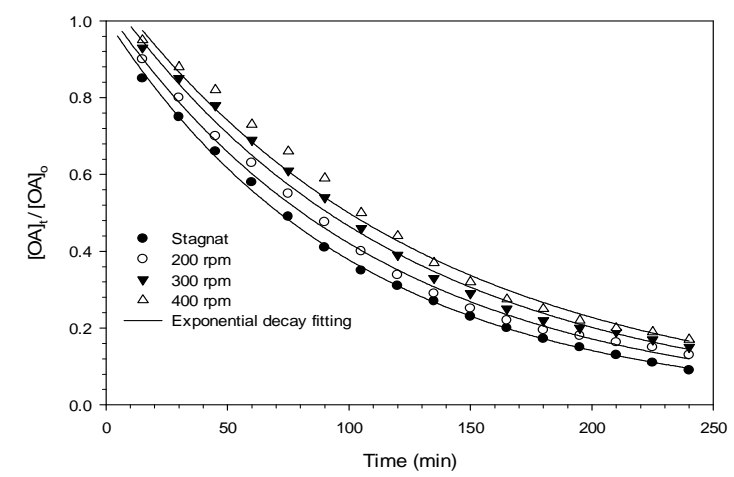

Figure 6. Normalized concentration $[\mathrm{OA}]_{\mathrm{t}} /[\mathrm{OA}]_{\mathrm{o}}$ against time curves, obtained at $[\mathrm{NaCl}]=1 \mathrm{~g} / \mathrm{L}, \mathrm{I}=30 \mathrm{~mA} / \mathrm{cm}^{2}, \mathrm{~T}=25^{\circ} \mathrm{C}$ and $[\mathrm{OA}]=0.1 \mathrm{M}$, for different rotation speeds.

\section{Effect of rotation speed on $O A$ removal}

The decrease in normalized $\mathrm{OA}$ concentration, $[\mathrm{OA}]_{t} /[\mathrm{OA}]_{\mathrm{o}}$, plotted against electrolysis time, with their exponential decay fitting at different rotation speed, is presented in Fig. 6. 
The relation between the rate constant and agitation is depicted in Table 3 and Fig. 7.

Table 3. Effect of agitation on the observed rate constant $\left(\mathrm{k}_{\mathrm{obs}}\right)$.

\begin{tabular}{|c|c|c|c|c|c|c|c|}
\hline Parameter & Value & $\begin{array}{c}\text { OA } \\
\text { removal } \\
(\%)\end{array}$ & $\begin{array}{c}\text { Rate constant } \\
\text { Kobs }_{\text {obs }} \\
\left(\mathrm{min}^{-1}\right) \times 10^{3}\end{array}$ & $\begin{array}{c}\text { Standard } \\
\text { error of } \\
k_{\text {obs }}\end{array}$ & $\mathbf{R}^{2}$ & $\begin{array}{l}\text { Sum of } \\
\text { square } \\
x_{10}^{3}\end{array}$ & Conditions \\
\hline \multirow{4}{*}{$\begin{array}{c}\text { Rotation } \\
\text { speed } \\
(\mathrm{rpm})\end{array}$} & 0 & 91 & 9.84 & $8.77 * 10^{-3}$ & 0.9989 & 2.30 & \multirow{4}{*}{$\begin{array}{c}{[\mathrm{NaCl}]=1 \mathrm{~g} / \mathrm{L},} \\
\mathrm{I}=30 \mathrm{~mA} / \mathrm{cm}^{2}, \\
\mathrm{~T}=25^{\circ} \mathrm{C},[\mathrm{OA}] \\
=0.1 \mathrm{M}\end{array}$} \\
\hline & 200 & 88 & 9.09 & $1.64 * 10^{-4}$ & 0.9953 & 9.10 & \\
\hline & 300 & 85 & 8.62 & $1.85 * 10^{-4}$ & 0.9935 & 13.30 & \\
\hline & 400 & 83 & 8.19 & $2.03 * 10^{-4}$ & 0.9914 & 17.71 & \\
\hline
\end{tabular}

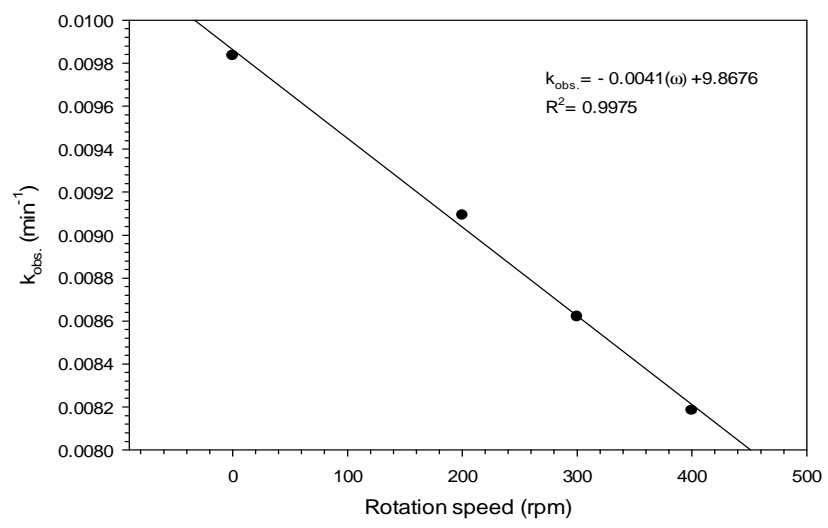

Figure 7. Effect of agitation on the reaction rate of $\mathrm{OA}$ electrochemical incineration; $[\mathrm{NaCl}]=1 \mathrm{~g} / \mathrm{L}, \mathrm{I}=30 \mathrm{~mA} / \mathrm{cm}^{2}, \mathrm{~T}=25^{\circ} \mathrm{C}$ and $[\mathrm{OA}]=0.1 \mathrm{M}$.

It is interesting to note that the absence of agitation gives higher rate constants, while increasing rotation speed more than $200 \mathrm{rpm}$ leads to a drastic drop in the reaction rate. These behaviors may be interrupted, as higher electrode rotation velocities would not enable the reaction of chlorine with OA, and a part of the formed chlorine would be liberated to escape outside the cell; hence, a lower reaction rate takes place. It is observed that there is a substantial inverse linearity between the rate constant and agitation.

\section{Effect of temperature on $O A$ removal and reaction kinetics}

The decrease in normalized $\mathrm{OA}$ concentration, $[\mathrm{OA}]_{\mathrm{t}} /[\mathrm{OA}]_{\mathrm{o}}$, plotted against electrolysis time, with their exponential decay fitting at different temperatures, is shown in Fig. 8.

The relation between the rate constant and temperature is illustrated in Fig. 9 and Table 4. A polynomial relationship between the rate constant and temperature was observed. The effect of temperature on OA anodic incineration was widely investigated by the group of De Battisti [22], in the presence of several anodes, Scialdone et al. [28], for the case of $\mathrm{DSA}_{-} \mathrm{O}_{2}$ anodes, and Canizares et al. [29], for BDD. According to literature data, the temperature effect on OA degradation strongly depends on the anodic material nature. With BDD, a temperature increase gave rise to a slight change in OA abatement [22, 29], while a drastic increase at $\mathrm{IrO}_{2}$ based anodes was observed $[22,28]$. In the present system, a 
drastic increase in $\mathrm{OA}$ abatement was observed in the presence of $\mathrm{NaCl}$. Therefore, $\mathrm{MnO}_{2}$ has a catalytic activity towards OA, which increased with higher temperatures.

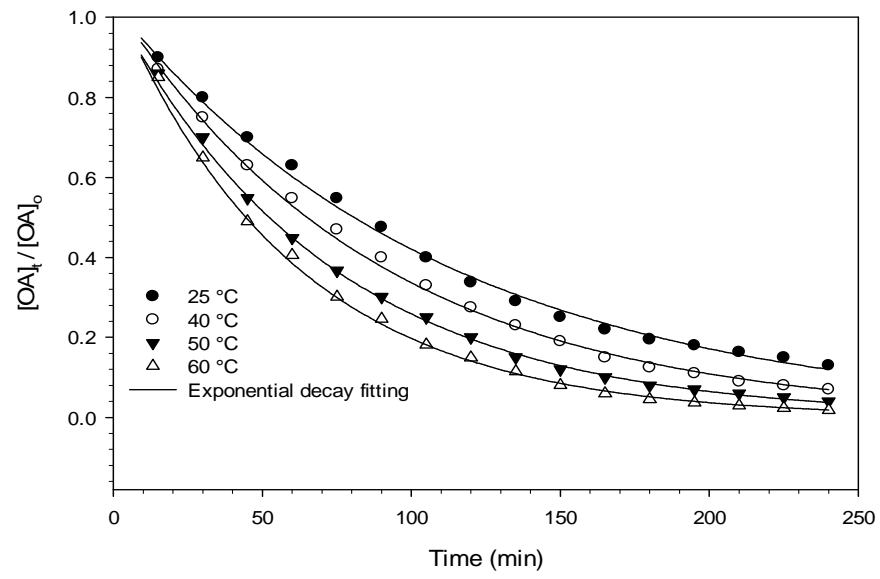

Figure 8. Normalized concentration $[\mathrm{OA}]_{\mathrm{t}} /[\mathrm{OA}]_{\mathrm{o}}$ against time curves, obtained at $\mathrm{I}=30$ $\mathrm{mA} / \mathrm{cm}^{2}, \omega=200 \mathrm{rpm},[\mathrm{NaCl}]=1 \mathrm{~g} / \mathrm{L}$ and $[\mathrm{OA}]=0.1 \mathrm{M}$, for different temperatures.

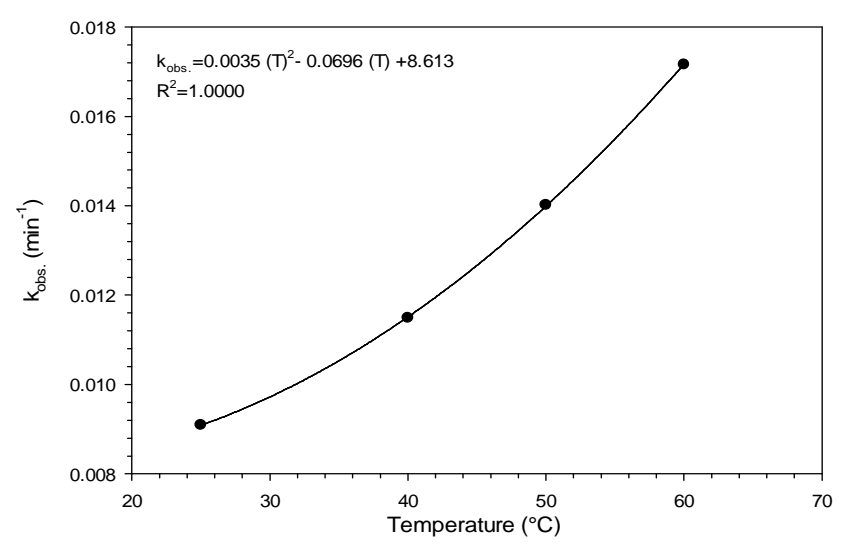

Figure 9. Effect of temperature on the reaction rate of $\mathrm{OA}$ electrochemical incineration; $\mathrm{I}=30 \mathrm{~mA} / \mathrm{cm}^{2}, \omega=200 \mathrm{rpm},[\mathrm{NaCl}]=1 \mathrm{~g} / \mathrm{L}$ and $[\mathrm{OA}]=0.1 \mathrm{M}$.

Table 4. Effect of temperature on the observed rate constant $\left(\mathrm{k}_{\mathrm{obs}}\right)$.

\begin{tabular}{|c|c|c|c|c|c|c|c|}
\hline Parameter & Value & $\begin{array}{c}\text { OA } \\
\text { removal } \\
(\%)\end{array}$ & $\begin{array}{c}\text { Rate constant } \\
\text { Kobs }^{-1} \\
\left(\mathrm{~min}^{-1}\right) \times 10^{3}\end{array}$ & $\begin{array}{c}\text { Standard } \\
\text { error of } \\
\text { kobs }\end{array}$ & $\mathbf{R}^{2}$ & $\begin{array}{c}\text { Sum of } \\
\text { square } \\
\text { x10 }^{3}\end{array}$ & Conditions \\
\hline \multirow{4}{*}{$\begin{array}{c}\text { Temperature } \\
\left({ }^{\circ} \mathrm{C}\right)\end{array}$} & 25 & 88 & 9.09 & $1.63 * 10^{-4}$ & 0.9954 & 8.96 & \multirow{4}{*}{$\begin{array}{c}{[\mathrm{NaCl}]=1 \mathrm{~g} / \mathrm{L}} \\
\mathrm{I}=30 \mathrm{~mA} / \mathrm{cm}^{2} \\
\omega=200 \mathrm{rpm} \\
{[\mathrm{OA}]=0.1 \mathrm{M}}\end{array}$} \\
\hline & 40 & 93 & 11.5 & $1.49 * 10^{-4}$ & 0.9976 & 5.72 & \\
\hline & 50 & 96 & 14.0 & $1.44 * 10^{-4}$ & 0.9985 & 3.64 & \\
\hline & 60 & 98 & 17.2 & $1.74 * 10^{-4}$ & 0.9986 & 3.82 & \\
\hline
\end{tabular}

The activation energy was calculated from the study of the temperature effect on the rate constant (Arrhenius' law), considering that the activation energy range of a typical diffusion-controlled process is less than $20 \mathrm{~kJ} / \mathrm{mol}$ [30]. Fig. 10 shows the relation between $\ln \mathrm{k}_{\mathrm{abs}}$ and the reciprocal of temperature (Arrhenius' plot). 
The data allowed estimating an activation energy of $14.541 \mathrm{~kJ} / \mathrm{mol}$, which confirms that the present system is limited by mass transfer [31].

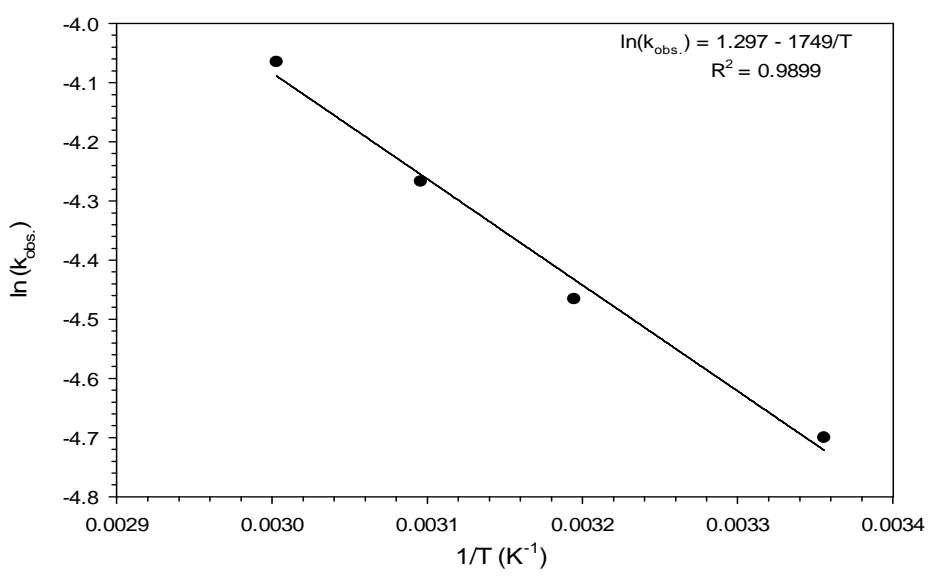

Figure 10. Arrhenius' plot between $\ln \left(\mathrm{k}_{\mathrm{obs}}\right)$ and temperature. $\mathrm{I}=30 \mathrm{~mA} / \mathrm{cm}^{2}, \omega=$ $200 \mathrm{rpm},[\mathrm{NaCl}]=1 \mathrm{~g} / \mathrm{L}$ and $[\mathrm{OA}]=0.1 \mathrm{M}$.

\section{Conclusion}

The present research confirmed that the rate constant of OA degradation reaction is directly proportional to the increase in $\mathrm{NaCl}$ concentration, current density, and temperature, while it is inversely proportional to the increase in the anode rotation speed. Two important points are worthy of attention: firstly, current density has a significant role on OA incineration in the present research, where a higher reaction rate can be achieved; secondly, temperature's influence shows a positive behavior, according to Arrhenius' law, in the current work, while an adverse effect was observed with other organic compounds, such as glucose [32], or no significant effect, in the case of anodes such as BDD [29]. This discrepancy between the present work and previous works may be attributed to the role of active chlorine in the electrochemical incineration, and to the catalytic activity of the $\mathrm{MnO}_{2}$ anode. Results of activation energy suggested that the reaction is controlled by the species diffusion towards the anode surface, and by their reaction with the active chlorine, while direct $\mathrm{OA}$ oxidation at the electrode surface is insignificant.

\section{Acknowledgments}

The authors wish to acknowledge the helpful suggestions and gracious technical assistance from the staff of the Chemical Engineering Department, College of Engineering, University of Baghdad, Iraq.

\section{References}

1. Chollier MJ, Epron F, Lamy-Pitara E, et al. Catalytic oxidation of maleic and oxalic acids under potential control of platinum catalysis. Catalysis Today. 1999;18:291-300. 
2. Xiong Y, Karlsson H. An experimental investigation of chemical oxygen demand removal from the wastewater containing oxalic acid using three phase dimensional electrode reactor. Adv Environ Res. 2002;7:139-145.

3. Raijeshwar K, Ibanez JG, Swain GM. Electrochemistry and the environment. J Appl Electrochem. 1994;24:1077-1091.

4. Martinez-Huitle CA, Ferro S. Electrochemical oxidation of organic pollutants for the wastewater treatment: direct and indirect processes. Chem Soc Rev. 2006;35:1324-1340.

5. Panizza M, Cerisola G. Application of diamond electrodes to electrochemical processes. Electrochim Acta. 2005;51:191-199.

6. Sotgiua G, Foderàb M, Marrab F, et al. Production and Characterization of Manganese Oxide-Based Electrodes for Anodic Oxidation of Organic Compounds. Chem Eng Trans. 2014;41:115-120.

7. Abbar AH, Salman RH, Abbas AS. Electrochemical Incineration of Oxalic Acid at Manganese Dioxide Rotating Cylinder Anode: Role of Operative Parameters in the Presence of NaCl. J Electrochem Soc. 2016;163:E333-340.

8. Fergus JW. Recent developments in cathode materials for lithium ion batteries. J Power Sources. 2010;195:939-954.

9. Wei W, Cui X, Chen W, et al. Manganese oxide-based materials as electrochemical super capacitor electrodes. Chem Soc Rev. 2011;40:16971721.

10. Chen CY, Wang SC, Tien YH, et al. Hybrid manganese oxide films for super capacitor application prepared by sol-gel technique Thin Solid Films. 2009;518:1557- 1560 .

11. Djurfors B, Broughton JN, Brett MJ, et al. Electrochemical oxidation of $\mathrm{Mn} / \mathrm{MnO}$ films: formation of an electrochemical capacitor. Acta Mater. 2005;53:957- 965 .

12. Nam KW, Kim KB. Manganese oxide film electrodes prepared by electrostatic spray deposition for electrochemical capacitors. J Electrochem Soc. 2006;153:A81- 88.

13. Chou SL, Cheng FY, Chen J. Electrodeposition synthesis and electrochemical properties of nanostructured c- $\mathrm{MnO}_{2}$ films. J Power Sources. 2006;162:727-734.

14. Xia H, Xiao W, Lai MO, et al. Facile synthesis of novel nanostructured $\mathrm{MnO}_{2}$ thin films and their application in supercapacitors. Nanoscale Res Lett. 2009;4:1035- 1040.

15. Xia H, Lai MO, Lu L. Nanostructured manganese oxide thin films as electrode material for supercapacitors. JOM. 2011;63:49-54.

16. Bonfatti F, Battisti A, Ferro S, et al. Anodic mineralization of organic substrates in chloride-containing aqueous media. Electrochem Acta. 2000;46:305-314.

17. Rajkurnae D, Palanivelu K, Mohan N. Electrochemical degradation of resorcinol using mixed oxide coated titanium electrode for wastewater treatment - A kinetic study. Ind J Chem Technol. 2003;10:396-401. 
18. Szpyrkowiez L, Juzzolino C, Kaul SN, et al. Electrochemical Oxidation of Dyeing Baths Bearing Disperse Dyes. Ind Eng Chem Res. 2000;39:32413248.

19. Cominiellis C. Electrocatalysis in the electrochemical conversion/combustion of organic pollutants for waste water treatment. Electrochem Acta. 1994;39:1857-1862.

20. Buso A, Balbo L, Giomo M, et al. Electrochemical Removal of Tannins from Aqueous Solutions. Ind Eng Chem Res. 2000;39:494-499.

21. Deborde M, Von Gunten U. Reactions of chlorine with inorganic and organic compounds during water treatment - kinetics and mechanism: a critical review. Water Res. 2008;42:13-51.

22. Martinez-Huitle CA, Ferro S, De Battisti A. Electrochemical incineration of oxalic acid. Role of electrode material. Eletrochim Acta. 2004;49:4027-4034.

23. Szpyrkowicz L, Radaelli M, Daniele S. Electrocatalysis of chlorine evolution on different materials and its influence on the performance of an electrochemical reactor for in direct oxidation of pollutants. Catalysis Today. 2005;100:425-429.

24. Scialdone O, Randazzo S, Galia A, Silvestri G. Electrochemical oxidation of organics in water: Role of operative parameters in the absence and in the presence of NaCl. Water Res. 2009;43:2260-2272.

25. Lente G. Deterministic Kinetics in Chemistry and Systems Biology. London: Springer; 2015.

26. Mohan N. Studies on electrochemical oxidation of acid dye effluent $(\mathrm{PhD}$ thesis). Chennai: Anna University; 2000.

27. Huang Y-H, Shih Y-J, Liu C-H. Oxalic acid mineralization by electrochemical oxidation processes. J Hazard Mater. 2011;188:188-192.

28. Scialdone O, Randazzo S, Galia A, et al. Electrochemical oxidation of organics at metal oxide electrodes: The incineration of oxalic acid at $\mathrm{IrO}_{2}-$ $\mathrm{Ta}_{2} \mathrm{O}_{5}\left(\mathrm{DSA}-\mathrm{O}_{2}\right)$ anode. Electrochim Acta. 2009;54:1210-1217.

29. Canizares P, Garcia-Gomez J, Lobato J, et al. Electrochemical oxidation of aqueous carboxylic acids wastes using diamond thin-film electrodes. Ind Eng Chem Res. 2003;42:956-962.

30. Ferreira M, Pinto MF, Soares OSGP, et al. Electrocatalytic oxidation of oxalic and oxamic acids in aqueous media at carbon nanotube modified electrodes. Electrochim Acta. 2012;60:278-286.

31. Benson SW. The Foundations of Chemical Kinetics. New York: McGrawHill; 1960.

32. Bonfatti F, Ferro S, Lavezzo F, et al. Electrochemical Incineration of Glucose as a Model Organic Substrate. II. Role of Active Chlorine Mediation. J Electrochem Soc. 2000;147:592-596. 